\title{
INEQUALITIES FOR SOME COEFFICIENTS OF UNIVALENT FUNCTIONS
}

\author{
JiAn-Lin Li, H. M. SRivastava AND YU-Lin ZhanG
}

Abstract. Let $\mathscr{S}$ be the usual class of normalized analytic and univalent functions in the open unit disk. We write

$$
\log \frac{f(z)}{z}=2 \sum_{n=1}^{\infty} \gamma_{n} z^{n} \quad(f \in \mathscr{S}) .
$$

The well-known de Branges' theorem shows that

$$
I_{n}=\sum_{k=1}^{n}(n-k+1)\left(k\left|\gamma_{k}\right|^{2}-\frac{1}{k}\right) \leqslant 0 \quad(n \in \mathbb{N}:=\{1,2,3, \cdots\} ; f \in \mathscr{S}) \text {. }
$$

In this paper we use the properties of $I_{n}$ to obtain some coefficient inequalities for univalent functions. The results obtained here extend and unify several known results.

Mathematics subject classification (1991): 30C45, 30C50, 30A10.

Key words and phrases: Analytic functions; univalent functions; coefficient inequalities; Bieberbach, Robertson, and Milin conjectures; de Branges' theorem; convex hull; Bazilević conjecture; fractional derivatives; Abel transformation.

\section{REFERENCES}

1] D. Aharonov, The de Branges theorem and uniqueness statements, J. Analyse Math, 46 (1985), 13-15.

[2] V. V. ANDREEV AND P. L. DUREN, Inequalities for logarithmic coefficients of univalent functions and their derivatives, Indiana Univ. Math. J., 37 (1988), 721-733.

[3] A. Baernstein, D. Drasin, P. Duren And A. Marden (Editors), The Bieberbach Conjecture, Proceedings of the Symposium on the Occasion of the Proof, Amer. Math. Soc., Providence, Rhode Island, 1986.

[4] K. S. CHUA, Derivatives of univalent functions and the hyperbolic metric, Rocky Mountain J. Math., 26 (1996), 63-75.

[5] X.-H. Dong, A remark on de Branges theorem, Acta Sci. Nat. Univ. Norm. Huan, 14 (1991), $193-197$.

[6] P. L. DuREn And Y. J. Leung, Logarithmic coefficients of univalent functions, J. Analyse Math. 36 (1979), 36-43

[7] S. Gong, A remark on Möbius transformations (I), Pure and Appl. Math. 1 (1985), 1-15 (in Chinese).

[8] W. K. Hayman And J. A. Hummel, Coefficients of powers of univalent functions, Complex Variables Theory Appl. 7 (1986), 51-70.

[9] Z. J. JAKUBOWSKI, On the upper bound for the functional $\left|f^{(n)}(z)\right|(n=2,3, \cdots)$ in some classes of univalent functions, Comment. Math. Prace Mat. 17 (1973), 71-80.

[10] J.-L. LI, On the logarithmic coefficients of univalent functions, Math. Japon. 42 (1995), 165-168.

[11] R. J. LIBERA AND E. J. ZLOTKIEWICZ, Early coefficients of the inverse of a regular convex function, Proc. Amer. Math. Soc. 85 (1982), 225-230.

[12] I. M. MiLIN, Some applications of theorems on logarithmic coefficients, Siberian Math. J. 32 (1991), 69-78. 
[13] I. M. MiLIN, Univalent Functions and Orthonormal Systems, Translations of Mathematical Monographs, Vol. 49, Amer. Math. Soc., Providence, Rhode Island, 1977.

[14] I. M. Milin AND A. Z. GRINSHPAN Logarithmic coefficients means of univalent functions, Complex Variables Theory Appl 7 (1986), 139-147.

[15] S. V. NIKITIN, Logarithmic coefficients of univalent functions, Soviet Math. (Iz.VUZ), 35(7) (1991), $38-43$.

[16] H. M. SRIVASTAVA, Fractional calculus and its applications in analytic function theory, in Proceedings of the International Conference in Analysis (Gyongsan; December 11-14, 1996) (Y. C. Kim, Editor), Yeungnam University, Gyongsan, 1996, pp. 1-25.

[17] P. G. TODOROV, On the modulus of the $n$th derivative of the univalent functions of the class $S$, Rev. Roumaine Math. Pures Appl. 38 (1993), 379-382.

[18] S. M. ZEMYAN, Estimates of logarithmic coefficients of univalent functions, Internat. J. Math. and Math. Sci. 16 (1993), 311-318. 